\title{
THE SUBSTANCE OF AUDITING IN PROJECT SYSTEM
}

\author{
Ashutosh Kumar Yadav, \\ Department of Computer Science \& Engineering, \\ Sachdeva Institute of Technology, \\ Dr. A P J Abdul Kalam Technical University, \\ Mathura, Uttar Pradesh, India.
}

\begin{abstract}
The estimation of a development is serious to its achievement. Hence, project administrations reflect this characteristic of handling project a critical instrument in completing the objects of the association from side to side project administration. Project audit measures the performance of the project with detail to its obtainable capitals. In other arguments, it offers an allinclusive reaction on project status. Such reaction allows high-ranking administration to make learnt judgement that will impulse the project in completing its objects. Though, around of the main profits of project auditing are as monitors; assistances progress the performance of the project, improves client and investor approval, saves prices, panels opportunity and circumvent opportunity sidle, offers primary difficult diagnostics, simplifies piece/ cost/ agenda relations, recognizes upcoming prospects for development, estimates performance of the project development team, updates consumer of project status/scenarios and reconfirms possibility of promise to project development. Development examiners are charged with the concern to review the project; for which the project administrator and development team should be helpful in imperative to boost the procedure.

The Observing and Assessment Strategy developed prior in the project should be castoff in this workout. Zones of the project where the examiners deficiency to the ability to investigation into auditing System, they can mention for a methodological auditing to be piloted in such zones.
\end{abstract}

ISSN: 2582-418X

Submitted: 01.03.2021

Accepted: 03.03.2021

Published: 03.03.2021
1

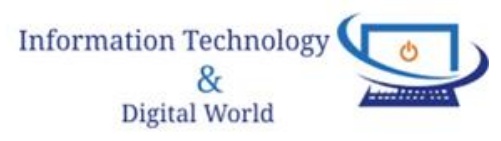


Journal of Information Technology and Digital World (2021)

Vol. 03/ No. 01

Pages: $1-11$

https://www.irojournals.com/itdw/

DOI: https://doi.org/10.36548/jitdw.2021.1.001

Keywords: Auditing; Concert; Development Modules; Reliable Audit; Review Data; Review

\section{Statement}

\section{Introduction}

Project reviewing assists as one of the main vehicles for the estimate of projects. It motivations on detailed valuation of the project in instruction for senior administration to institute how well the project is responsibility in positions of concert. The examiners matched the current status of the project with its strategic actions to found whether the scheme is distributing its deliverables on timetable, price, possibility and excellence. The conclusions of the examiners should be prepared identified to the project team, to make their inputs and response to a round of the interesting queries modelled by the examiners previously the account will be advanced to senior administration for conclusions to be engaged. Examiners are acceptable to mention and not mark judgement on the project; relatively, judgements are completed by the administration of the association. The approvals of the auditors should be preserved with supreme significance, as they have engaged their time and properties to separate those zones of the project that are not performing. In adding, project administrators and team should not understand supervising are competitors but relatively people who are there to accompaniment their effort on the scheme. As such, should be agreed the essential support required to assume this project for the good of the association. [10]

\subsection{Development Modules and when it would be conducted}

Project inspecting mentions to the methodical assessment into the ways project supervision morals are realistic to the project. It includes detailed analysis method to found best performs and attends as support to sustenance supervision conclusions required for the project. There is no „greatest" period to behavior an inspection; though, utmost project checks are directed at the twitch of the project, [9] future in the project and afterward the project is finalized, dependent on the succeeding:

- The landscape and extent of the project

- To confirm that all essential methodological problems are determined before scheduled per the project. this essentially strengthens the necessity for the initial inspection. [1]

Information Technology 
Journal of Information Technology and Digital World (2021)

Vol. 03/ No. 01

Pages: 1-11

https://www.irojournals.com/itdw/

DOI: https://doi.org/10.36548/jitdw.2021.1.001

- Providing the parental association with the compulsory specifics as to whether the project is compliant to the prearranged timetable, reasonable, possibility and excellence limitations. This mentions to the late-night review typically conducted throughout the scheme.

- Follow up per the guidelines set organized with the customer. Most consumers request for such assessment and its typically called the support project assessment. [8]

The paramount period to behavior such review can be resolute by project Development investors such as the parent association, project supervisor and crew. Scheme review should not be realized as an ultimate decision on the concert of the project supervisor and team member but somewhat a knowledge bend experience. As such should be contained by all for the respectable of the project. [7]

\subsection{Statistics convenience for project audits}

Convenience to applicable project Development modules is essential to the correctness of project assessment. However, it is interesting specially when trade with government related projects. [5] Files gathering which is the backbone workout for each reliable inspection, dishonesties in the needles of the audit team. Uniform nevertheless, [6] the project team member must deliver the auditor with the essential project particulars for the efficiency of the development, the audit crew should gross the clue. The audit crew must have entree to all project papers counting:

- Introductory project papers such as Appeal for Tender (AFT), notes of project panel conferences and other methodological papers from senior administration

- The project strategy and extra papers work settled through the development of project operation

- Status information on the project and other significant practical manuscript

Evidence meeting is a discouraging workout that necessity be accepted by the assessment crew in instruction to safeguard an actual and reliable audit. Approximately administrations have sturdy guidelines to inhibit developers since finishing data and other pamphlets that are desirable by the inspection crew. The audit crew should have free admission to evidence concerning the project

Information Technology 
Journal of Information Technology and Digital World (2021)

Vol. 03/ No. 01

Pages: 1-11

https://www.irojournals.com/itdw/

DOI: https://doi.org/10.36548/jitdw.2021.1.001

excluding then quantified; it is their accountability to decode what is convenient to their work or not. [11]

\subsection{Project assessment lifecycle}

Lifecycle is a report of the dynamic stages of the inspection procedure. Respectively stage is overloaded with sequence of actions that obligation be talented for the course to be thought fruitful. So, the stages of the inspection lifecycle and its linked events as definite by (PRADHAN, 2017) are therefore:

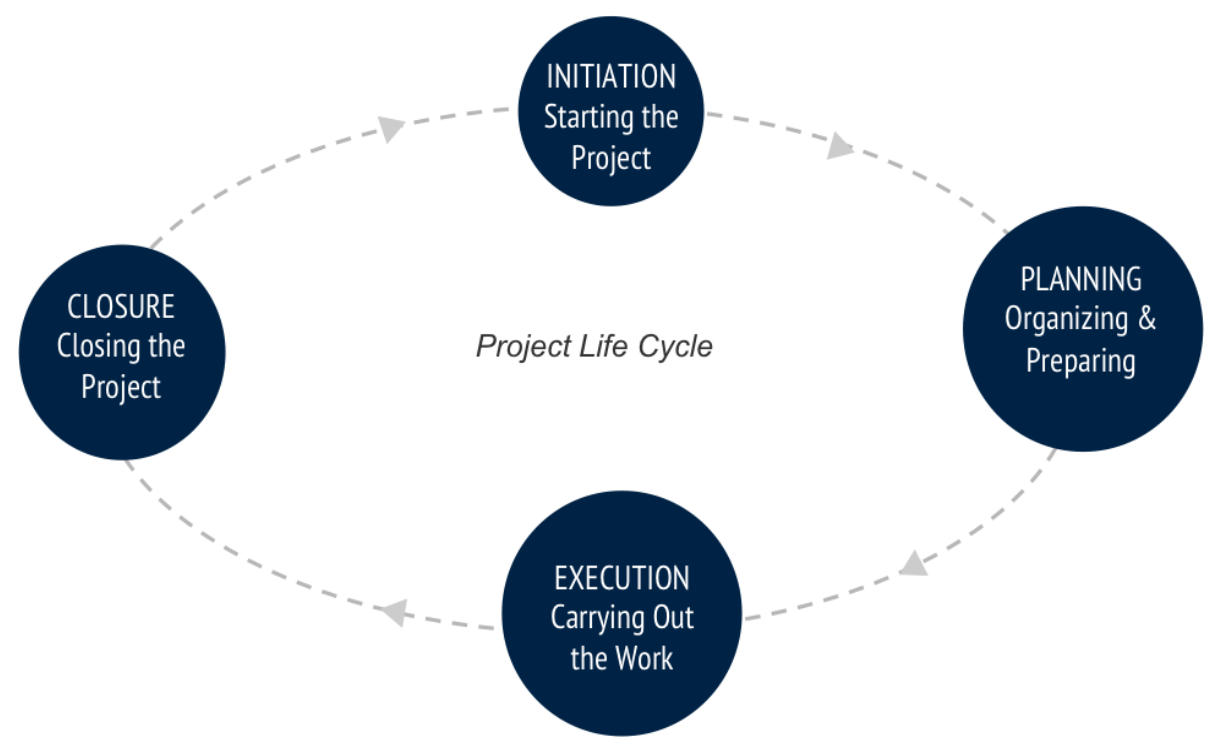

Figure-1.1

1) Inspection instigation: This is the initial stage that signs the start of the whole inspection procedure and it contains the following actions:

a) Describes the what, where, when and how the inspecting procedure should drive. The drive of the inspecting should be obviously defined for the inspection crew to know their objective.

b) The opportunity of the inspection should be recognized. Whether the inspection is concentrating on exact zones of the project or the whole project. Whether the inspection is analytical into profounder features or fair shallow zones of the project. Inspecting profounder zones of the project needs methodological and very knowledgeable project inspectors. [4] The thinner the inspection 
Journal of Information Technology and Digital World (2021)

Vol. 03/ No. 01

Pages: 1-11

https://www.irojournals.com/itdw/

DOI: https://doi.org/10.36548/jitdw.2021.1.001

possibility, the smaller the tasks confronted by the inspectors while comprehensive inspection possibility are riskier and additional monotonous to achieve. [12]

c) Statistics gathering is an essential module of the complete procedure and that receipts place at this stage of the inspection lifecycle. [2]

d) Inspecting function and observes appropriate for inspecting the project are traditional in this stage of the procedure.

e) Guidelines, rules and other inspecting procedures are major function at this phase. Hence, associates of the inspection crew should be entirely cognizant of the pounded guidelines leading the procedure to confirm obedience and operative inspection workout. [13]

2) Model description of the project: These stage attentions on the founding of actual benchmarking strictures castoff to measure the project.

3) Inspection database: Once the measures for the valuation of the project are recognized then, a database should be

created to allow the inspection crew in clearing its responsibilities. The information collected in the original phase of the check exercise should be stored in this database for the appraisal of:

a) The administration of the project

b) The modern and forthcoming status of the project

c) The project agenda, economical and excellence in relations of its concert and conference customer's necessities

4) Planning organizing preparing of the project: Once strictures are established and valued information together formerly, conclusions can be complete from a knowledgeable situation. Inspectors are not the ones production conclusions but relatively current the truths for eldest supervision to variety conclusions concerning the project [15]

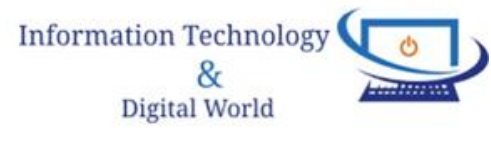


Journal of Information Technology and Digital World (2021)

Vol. 03/ No. 01

Pages: 1-11

https://www.irojournals.com/itdw/

DOI: https://doi.org/10.36548/jitdw.2021.1.001

5) Execution carrying out work of the inspection report: This contains ordering the truths about the project and pushing it in an arrangement called inspection report. This arrangement should be accepted by the organization before existence castoff by the project inspection crew.

6) Closure of the inspection: This includes carrying to a near the whole inspection procedure. Though, it can only be finished when the statement has been correctly studied, references addressed and unconfined by administration.

\subsection{Modules of the audit status report}

The audit status report is a substantial manuscript that delivers organization and additional investors of the project with the obligatory information about the development completed so far on the project. Such evidence can assistance carry back the project on pathway in suitcases of aberration.

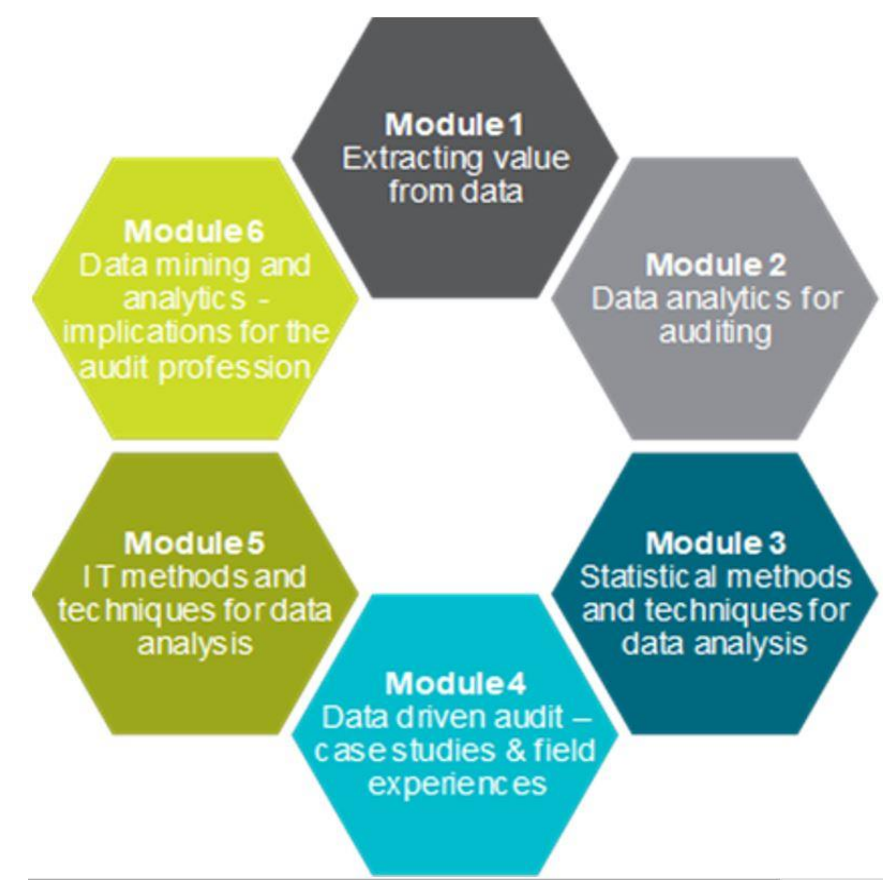

figure -1.2

- Extracting value from data: This attention on the universal outline of the project together with the extracting data value and objects of the project. It should be modest and strong for

Information Technology $\&$
Digital World 
Journal of Information Technology and Digital World (2021)

Vol. 03/ No. 01

Pages: 1-11

https://www.irojournals.com/itdw/

DOI: https://doi.org/10.36548/jitdw.2021.1.001

altogether to comprehend. This feature should be healthy printed to deliver booklovers with the drive for which the project was started.

- Data analytics for Auditing status: Four significant constraints are measured here; these are price, timetable, development and superiority. Each project has an economical and hence, construction project price a substantial restraint in project supervision.

- Statistical methods and techniques for data analysis: This opinion to the assessor's take on what should be done in the project. The previous method used that controlled to some unfinished responsibilities should be improved or altered in instruction to realize achievement inside timetable and economical.

- Administration issues: All project subjects that need the consideration of eldest supervision specially person's principal to the achievement of the project. In adding, choices touching the timetable, price and presentation of the project should be complete by supervision.

- Threat administration: Valuation of threats linked with the project Development and how such must be alleviated in instruction to save the project.

- Project conventions and limitations: Asserting the situations beneath which this description is thought true. It is the responsibility of the assessor to verify the correctness of this file by confirming the situations or molds complete in this information. It is substance observing that, the clarification of this information dishonesties completely with senior administration and not the assessor. The inspector offerings the actualities for forward proposal to administration for suitable decisions. [5]

\subsection{The essential circumstances of a credible project assessment}

A project assessment is measured credible when it is accompanied in the utmost suitable custom commendable of senior supervision approval. (Meredith \& Mantel (Jr.), 2009) place onward around of the circumstances essential for a credible project inspection and these are:

1) Accurate choice of the inspection crew: This is ultimate to the achievement of the assessment method and it contains the following: 
Journal of Information Technology and Digital World (2021)

Vol. 03/ No. 01

Pages: 1-11

https://www.irojournals.com/itdw/

DOI: https://doi.org/10.36548/jitdw.2021.1.001

a) Collection of inspection crew members should be founded on capability and not simple obtainability.

b) Inspection crew members essential acquire not to project their special opinions or thoughts in the procedure; but relatively should sensibly perceive and information therefore deprived of partiality.

c) Inspection crew necessity abstain from battles and additional particular miss-happenings with project operate; such depravities will reason stiffness and infrequent conflicts that can lead to superfluous interruption and ultimate alteration of the procedure. [16]

\subsection{Procedures to overawed project inspecting challenges}

Project crew members frequently impression jittery or agitated when a review workout is led on the project they are management. Such insight from the project crew can disturb the audit crew in receiving entree to the evidence required to prepare their work. Project crews frequently understand the audit operation as a strategy to representation their shortfalls and deficiencies. Therefore, the following procedures should be followed to help decrease such discernment:

- Grow the project crew to obviously appreciate the possibility of the review.

- Short-term the project crew on how you propose inspecting the project.

- Kind of assured you current the inspection conclusions to the project crew for their inputs and imaginable clarifications.

- Circumvent by means of pejorative or depreciating terminology; as this will make pressure and preventable trouble, that will delay the inspection development.

- The exterior assessor should confirm every data assumed so as to eliminate preconception and fallacious data.

\subsection{How to proficiently manage project inspection information}

Data gathering is an intimidating procedure particularly when leading audit workout on a project. Nevertheless, it is a requirement do workout in instruction to current a credible and dependable audit report. Satisfactory period should be allotted to it in instruction to become the suitable results. This period can be best applied when the workout is done in a disciplined method or else it will

Information Technology $\&$ Digital World 
Journal of Information Technology and Digital World (2021)

Vol. 03/ No. 01

Pages: 1-11

https://www.irojournals.com/itdw/

DOI: https://doi.org/10.36548/jitdw.2021.1.001

quantity to unused of period. This prepared technique of statistics treatment as put headlong by (Meredith \& Mantel (Jr.), 2009) includes:

- Proficient particle classification of together data on the project so as to ease approachability.

- Statistics should be classified into ,valuable ${ }^{e e}$,,furthermost beneficial ${ }^{\text {ee }}$ in instruction to confirm suitable supervision.

- Procedures should be occupied to preclude replication of data that will result in time wastage.

- Situation satisfactory activities essential to legalize the perfect development in relations of evidence propagation.

\subsection{The cost/benefits inquiry of project estimation/inspection}

Estimation is a crucial component of each project geared to realizing project objects. Consequently, it's authoritative for the project executive to certify that exhaustive estimation workouts are accompanied intermittently on the project. Approximately of the assistances of project estimations are conferred above; [14]

\subsection{Fitting farm duties of project auditors}

(Keller \& Pyzdek, 2013) placed onward around of the principled errands of an assessor and they are as follows:

- The trailblazer of the inspection crew should be smooth plentiful to categorize misinterpretations amongst crew members and act promptly to determination such topics. Underrating such, can prime to thoughtful contests that will avoid the auditing crew in realizing their crucial detached

- Audit crew leaders must establish equality when relaxing argument amongst memberships. The issue should be considered without partiality in instruction to keep the project [17]

\section{Conclusion}


Journal of Information Technology and Digital World (2021)

Vol. 03/ No. 01

Pages: $1-11$

https://www.irojournals.com/itdw/

DOI: https://doi.org/10.36548/jitdw.2021.1.001

In The Substance of Auditing in Project System, we have projected the development and growth stream which could be followed to kind of the project observing and regulatory of software construction development in a software company. and Training for Observing project beside scheme and administration curative actions till closure are simplified. Lastly, all developments are bendable, means, they may be changed to the conferring to the work of the company new version to be changed the old version if compulsory or any problem to the current version. And also we are developing software to modules permitting to the company requirement methods that is follow in the company norms

The assistances of project assessments are noticeable in large governments undertaking big projects. In such belongings, manifold inspections are suggested, possibly one per stage. Persons inspecting projects should be conversant with a round of the project administration ideologies and practices habituated to classify incorrect approaches used to device project.

\section{References}

[1] Aramyan, P. (2016, July 25). Project Management Blog. Retrieved from easyprojects: https://explore.easyprojects.net/blog/what-are-project-controls-why-are-they-soimportant-in-project-management-and-how-to-deal-with-them

[2] Keller, P., \& Pyzdek, T. (2013). The Handbook for Quality Management. McGraw-Hill.

[3] Meredith, J. R., \& Mantel (Jr.), S. J. (2009). PROJECT MANAGEMENT A Managerial Approach Seventh Edition. 111 River Street, Hoboken, NJ United States Of America: John Wiley \& Sons, Inc.

[4] PRADHAN, M. K. (2017). Project Management.

[5] project-management.com. (2018, October 8). The Project Baseline - A Project Management Definition.

[6] QAI (India) - "The essentials of Project Management".

[7] Watts S. Humphrey, Pearson Education- "Introduction to the Personal Software Process".

[8] QAI (India)-“Software Metrics".

[9] Organization Procedure Project Monitoring and Control- AVL India Software Private Limited.

Information Technology \& Digital World 
Journal of Information Technology and Digital World (2021)

Vol. 03/ No. 01

Pages: 1-11

https://www.irojournals.com/itdw/

DOI: https://doi.org/10.36548/jitdw.2021.1.001

[10] CMMI Project Monitoring and Control - http://www.software-qualityassurance.org/cmmi-project-monitoring-and- control.html.

[11] S. Gopalakrishnan - Key Best Practices@ Polaris Software driving Operational Excellence, CSI Article January 2010.

[12] Project Monitoring Control process overview www.cse.iitb.ac.in/ cs682/reading/2- OtherProcesses.ppt

[13] Oracle 8i Complete Reference from Oracle Press

[14] System Analysis and Design by Elias M. Edward

[15] Software Engineering a Practitioner Approach by Roger S. Pressman.

[16] Professional JSP from WROX Press.

[17] Complete Reference JAVA 2 from TMH. 